•综述・

\title{
叶绿体DNA标记在谱系地理学中的应用研究进展
}

\author{
胡 颖 1,2 王 茜 ${ }^{1,2}$ 张新新 1,2 周 玮 ${ }^{1,2}$ 陈晓阳 ${ }^{1,2}$ 胡新生 ${ }^{1,2}$ \\ 1 (广东省植物种质资源与利用重点实验室, 广州 510642) \\ 2 (华南农业大学林学与风景园林学院, 广州 510642)
}

摘要: 谱系地理学研究旨在探究历史上发生的影响目前遗传谱系系统发育和空间分布格局关系的生态与进化过 程。叶绿体DNA具有单亲遗传、低突变率、单倍体等特征, 其分子标记不同程度地保留着植物长期进化的历史遗 传痕迹, 有助于深度解析谱系地理变异的形成机制。本文探讨了上述特征是怎样影响分子标记的选择、扩大或缩 小群体遗传结构分化、延长或缩短空间基因溯祖时间、促进或阻碍种间基因渐渗及谱系分选(复系、并系和单系 形成)进程, 重点阐述了这些影响过程的理论基础, 并结合实际例子阐述谱系地理研究进展。由于位点间在突变 率、选择强度及它们与漂变互作等方面存在异质性, 今后一个研究重点就是基于叶绿体全基因组序列分析谱系地 理变化格局, 包括分析DNA位点间的基因渐渗或基因流动程度差异分布及沿着叶绿体DNA序列上谱系分选差异 分布。

关键词: 叶绿体; 谱系地理学; 杂交带; 基因溯祖理论; 物种形成

\section{Advancing phylogeography with chloroplast DNA markers}

\author{
Ying $\mathrm{Hu}^{1,2}$, Xi Wang ${ }^{1,2}$, Xinxin Zhang ${ }^{1,2}$, Wei Zhou ${ }^{1,2}$, Xiaoyang Chen ${ }^{1,2}$, Xinsheng $\mathrm{Hu}^{1,2^{*}}$ \\ 1 Guangdong Key Laboratory for Innovative Development and Utilization of Forest Plant Germplasm, South China \\ Agricultural University, Guangzhou 510642 \\ 2 College of Forestry and Landscape Architecture, South China Agricultural University, Guangzhou 510642
}

\begin{abstract}
Phylogeography seeks to identify the historical ecological and evolutionary processes underlying modern-day phylogenetic relationships across a spatial gradient. Owing to the characteristics of uniparental inheritance, low mutation rates and haploid, chloroplast DNA (cpDNA) markers record the events occurring in historical long-term evolutionary processes to different extents, and hence aid in understanding the mechanisms for phylogeographic variation. Here we discuss how these characteristics affect cpDNA marker selection, how they increase or reduce population genetic differentiation, how they lengthen or shorten the average gene coalescent times, how they promote or impede gene introgression among species and how the process of lineage sorting functions from polyphyly to paraphyly to monophyly. We reviewed the theoretical bases of these mechanisms, as well as the progress made in empirical studies regarding the theories of phylogeographic variation. Because of the heterogeneity of DNA sites in mutation rate, selection strength and interactions with genetic drift effects, one study to examine the genome-wide pattern of phylogeography will be necessary in the future. This must include the analysis of differential gene introgression and gene flow among sites, as well as the distribution of the differential phases of lineage sorting along the chloroplast genome.
\end{abstract}

Key words: chloroplast; phylogeography; hybrid zone; gene coalescent theory; speciation

谱系地理学是指比较遗传谱系(genetic lineages) 系统进化及与其对应的谱系地理位置的关系, 以寻 找影响现有谱系(基因、群体或物种)进化关系与空
间分布的主要机制(Avise et al, 1987; Avise, 2000), 重点研究历史上发生的生态与进化过程(漂变、迁 移、突变和选择)对目前谱系遗传变异分布格局的影

收稿日期: 2018-12-02; 接受日期: 2019-02-12 
响, 因此谱系地理研究包含谱系遗传进化时间和谱 系分布空间两方面的信息(Freeland et al, 2011)。目 前研究植物谱系地理变异过程中发生的历史事件, 除了参考地质运动、气候变化和古化石资料等外, 分子遗传标记的应用提供了一个重要分析途径。这 与分子标记的遗传变异特点紧密相关, 如分子标记 的遗传方式、突变与重组率及选择适应性或中性等, 这些特点使得分子标记不同程度地保留着谱系长 期进化的遗传痕迹, 有助于深度解析谱系遗传分化 形成历史。最近 20 多年来, 尤其是高通量测序技术 的应用和发展，使得部分或全基因组序列分析在非 模式植物上成为可能, 可获得在群体和种水平上大 量的单核苷酸位点(SNP)及大样本数据, 可在基因 组水平上深入解析谱系地理变异, 研究单物种或多 物种遗传谱系地理变异模式(Lexer et al，2013; Garrick et al, 2015)。

已有的相关文献显示叶绿体DNA (cpDNA) 标 记的应用对谱系地理变异研究有显著的贡献 (Garrick et al, 2015)。与核DNA (nDNA)标记相比, cpDNA标记具有以下特点: (1)单亲遗传, 在裸子植 物中呈父系遗传, 群体间基因流可通过花粉和种子 流来实现，种间可通过授粉杂交进行基因交换。在 被子植物中, cpDNA多数呈母系遗传, 群体间基因 流只通过种子流动实现, 少数呈双亲遗传, 基因流 可通过花粉和种子流来实现。Corriveau和Coleman (1988)在所调查的 235 种被子植物中估计有 $14 \%$ 的 质粒DNA呈双亲遗传。(2)基因组较小, 在高等植物 中为 120-220 kb, 在绿藻中为85-292 kb (Palmer, 1985), 基因组所含的功能基因数目少。目前植物 cpDNA全基因组测序在基因库中持续增加, 为种间 和种内的地理变异与进化研究提供了基础。(3)突变 率低, 年单核苷酸位点同义密码子突变率一般在 (1.0-3.0) $\times 10^{-9}$ (Wolfe et al, 1987) , 但许多植物 cpDNA也存在多态的卫星DNA区域(Provan et al, 2001; Chmielewski et al, 2015), 可用于研究种内谱 系地理变异。(4)有效群体 $N_{e f}$ (母系遗传)或 $N_{e m}$ (父系 遗传)小, 可以是nDNA有效群体 $\left(N_{e}\right)$ 的 $1 / 4$ (亲本性 别比1：1时), 因而表现出较大的遗传漂变效应 $\left(1 / N_{e f}\right.$ 或 $\left.1 / N_{e m}\right)$ 。例如, 从现存群体分布中随机抽取 的 2 个 cpDNA基因来自同一祖先拷贝的平均时间 $\left(N_{e f}\right.$ 或 $\left.N_{e m}\right)$, 即平均溯祖时间(mean coalescent time), 要比随机抽取的 2 个 nDNA 基因的平均溯祖时间 $\left(4 N_{e}\right)$ 短(Tajima, 1983), 可导致cpDNA与nDNA在种 内遗传变异和种间遗传分化不一致的结果。以上特 征为cpDNA标记在谱系地理变异研究中的应用奠 定了基础。

Beheregaray (2008)和Hickerson等(2010)对谱系 地理学发展做了较全面的综述, 内容包括多个物种 的实际调查、谱系地理学科形成的理论基础与统计 检验、谱系地理学与生态和进化生物学不同研究领 域的整合(如与群落生态学和生态新种形成的整 合)。本文将从cpDNA标记的应用角度来探讨其所 能揭示的谱系地理变异信息，在已发表的综述基础 上做更为具体的理论与分子标记应用分析。首先讨 论叶绿体基因组结构与分子标记选择的关系，因为 篮选合适的分子标记是谱系地理研究的前提，其次 讨论遗传谱系在空间分布的群体结构与基因溯祖 (gene coalescence)进化的关系, 然后分析谱系在特 定遗传结构下的地理变异，即杂交带(hybrid zone) 与基因渐渗(gene introgression), 最后讨论由种内群 体结构分化的微观进化(microevolution)延伸到更大 群体遗传分化下的宏观进化(macroevolution), 即物 种形成，探讨 cpDNA在谱系分选(lineage sorting)与 物种形成进程方面的研究进展, 分析相关应用的理 论基础，并展望叶绿体DNA标记今后的应用。

\section{基因组结构与分子标记}

寻找cpDNA在种内或种间变异的多态性标记 是谱系地理变异研究的前提(Schaal et al, 2010)。至 今有关叶绿体基因组的结构已有大量报道，但基本 认识没有太大变化(邢少辰和Liu，2008)。大多数植 物叶绿体DNA为闭环双链DNA, 一般由4部分组成, 即 2 个反向重复区 $\left(\mathrm{IR}_{\mathrm{A}}\right.$ 和 $\left.I R_{B}\right)$, 其上编码 2 套 $r R N A$ 的 基因，1个大单拷贝区(LSC) 和 1 个小单拷贝区 (SSC)。少数植物没有 IR区, 即仅有一段编码 1 套 rRNA基因的序列区, 如蝶形花冠植物(Lavin et al, 1990)和松科树种 (Strauss et al，1988)。在裸藻 (Euglena gracilis)等低等植物中却有3个同向重复区, 共编码了3 套rRNA基因拷贝(Palmer, 1985)。IR扩张 或丢失的机理过程(倒位与重复)比较复杂, 很少有 研究报道(Wang et al, 2008)。至今仍认为叶绿体多 数基因通过与核内共生基因转移方式(endosymbiotic gene transfer)转到核DNA上(Huang et al, 2003), cpDNA本身只保留了很少的基因(Martin et al, 
2002)。已知LSC和SSC区的单个位点的平均突变率 要比IR区要大(Perry \& Wolfe, 2002), IR区比LSC和 SSC区更趋于保守。

cpDNA不同区域存在异质突变率, 为选择合适 的分子标记提供了基础。由于IR区单位点的平均突 变率要比LSC或SSC区低, 用于研究种内基因或群 体谱系地理变异的多数分子标记选在LSC非编码区， 少数在SSC非编码区, 而用于种间谱系进化的多数 分子标记选在LSC或SSC区的编码区域。Byrne和 Hankinson (2012) 调查了澳洲檀香 (Santalum spicatum)、尖荚相思树(Acacia acuminata)、斜脉桉 (Eucalyptus loxophleba)、边缘桉(E. marginata)、肖 牙刷树 (Calothamnus quadrifidus) 及圆叶金银花 (Lambertia orbifolia) 等不同种内的13个被认为有高 度变异的非编码区域, 发现在LSC区的基因间隔区 (trnV-ndhC、trnQ-rps16、rpl32-trnL、ndhF-rpl32、

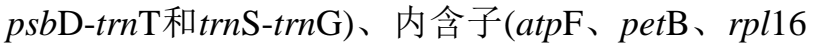
和petD)及SSC区 $n d h A$ 内含子标记都可用于研究这 些植物种的谱系地理变异。LSC编码区也包含简单 重复序列(simple sequence repeats, SSR)变异, 可用 于种内谱系地理变异研究, 至今已有较多报道 (Provan et al, 2001; Huang et al, 2015)。目前, 常用于 种间进化关系的标记或作为物种识别的条形码有 LSC区编码基因 $r b c \mathrm{~L} 、 m a t \mathrm{~K} 、 p s b \mathrm{~A}$ 和trnL-F基因间 隔区，及LSC和IR连接区标记psbA-trnH (Wang et al, 2013)。应用 IR内的编码或非编码区域的多态性标记 的研究很少。

除突变率差异外, 标记的选择适应性会影响其 通用性。一般认为内含子和基因间隔区的标记为中 性标记, 容易在种内呈现出多态性, 适合多数植物 种的谱系地理研究(Yang et al, 2015); 但如果中性 标记与选择适应性基因或有害突变基因紧密连锁 的话，遗传搭乘效应 (genetic hitchhiking effect, Flood et al，2016)或背景选择效应 (background selection, Charlesworth et al, 1993)会使得这些标记 呈现出适应性基因的特征。遗传搭乘效应指随着适 应位点上有益突变基因频率的升高, 其附近紧密连 锁的中性位点遗传多样降低; 背景选择效应指随着 适应位点上有害突变基因频率的降低, 紧密连锁的 中性位点遗传多样降低。这种现象在麦瓶草属 (Silene) cpDNA中的LSC区trnT-trnL-trnF 非编码区 有报道(Muir \& Filatov, 2007), 存在选择性清除效 应(selective sweep effects), 即某核苷酸位点强的正 选择导致其附近位点的遗传变异降低或消除。这些 标记在种内的遗传变异小, 不适合种内基因或群体 地理变异研究。以功能基因编码区或编码片段为标 记，种内多态性都小，一般不适合种内谱系地理变 异分析，但适合于种间系统进化分析。若突变等位 基因有益或有害，如LSC区的 $r b c \mathrm{~L}$ 和 $m a t \mathrm{~K}$ 等基因 (Bock et al, 2014), 正选择(positive/Darwin selection) 或纯化选择(purifying selection)使有益等位基因快 速趋于固定，以这些基因或其片段作为分子标记， 适合用作种间识别条形码。

遗传漂变也会影响分子标记选择，当物种种群 小时，中性标记遗传多样性小，篮选到有效分子标 记的概率变小。对于适应性基因标记，遗传漂变可 降低自然选择的作用，提高有害突变等位基因的 固定概率，使得小群体与大群体间趋于固定不同 的等位基因，导致种间条形码的笁选和应用分析复 杂化。

与遗传漂变效应不同, 种内群体间基因流(单 倍体的花粉流和二倍或多倍体的种子流)导致群体 间遗传组成趋于同化，而通过杂交实现的种间基因 流(花粉流)导致种间谱系分化程度减小，两者都有 助于维持 $\mathrm{cPDNA}$ 多态性和标记䇻选。但与遗传漂变 作用过程一样，基因流作用于整个叶绿体基因组的 遗传变异, 来自遗传分化群体的迁移基因组可提高 接受群体的遗传多样性。

\section{2 群体结构与基因溯祖}

谱系地理分析中的一个重要部分就是揭示谱 系在空间的分布特点以及其空间分布怎样影响谱 系遗传进化关系。植物种在地理空间的分布可以是 离散、连续或二者的混合, 其形成原因既有物理因 素(如山体与河流阻隔), 又有生物因素(如异质生境 和物种竞争)。在同质生境和群体连续分布情况下, 有限的基因流可形成内在的群体遗传结构。考虑从 物种分布区内随机抽取 $n$ 个基因(连续分布)或抽取 $L$ 个样本, 每个样本 $n$ 个基因(离散分布), 其群体遗传 结构可以用遗传分化系数 $F_{s t}$ 来表示。连续分布群体 的 $F_{s t}$ 计算需要应用邻近个体数(neighbourhood size; 一定范围内的个体数量, 该范围内的中心区域个体 的亲本数类似于随机抽取的样本，相当于 $N_{e}$ ) (Wright, 1969)。胡新生(2002)对群体结构的理解有 
详细评述。若在时间上回溯, 所有抽取的基因样本 都可追溯到最近共同祖先 (most recent common ancestor), 种内基因扩散(连续分布)或群体间基因 流(离散分布)除了改变基因地理空间位置关系外, 也可以改变整个样本的溯祖时间(谱系进化关系)。

一个隔离的随机交配群体在纯漂变(中性)过程 下, 2 个 сpDNA基因的平均溯祖时间为 $N_{e}$ 世代(群体 雌雄性别比 $1: 1$ ), 2 个nDNA基因的平均溯祖时间为 $4 N_{e}$ (Tajima, 1983)。群体结构的存在不同程度地改 变了它们在中性条件下的相对平均溯祖时间。理论 上已证明，对于离散分布群体，中性cpDNA基因的 群体遗传结构分化延长了其平均溯祖时间 $E(T)$ :

$$
E(T)=\frac{2 \tilde{N} L}{1-G_{s t}}\left(1-\frac{1}{n}\right)
$$

式中, $G_{s t}$ 为群体遗传分化系数 (在单个位点存在多 于 2 个等位基因情况下的遗传分化系数), 其计算公 式如下:

$$
G_{s t}=\left(1+2 \tilde{N} \frac{L}{L-1}\left(\frac{L}{L-1} \tilde{m}+\mu\right)\right)^{-1}
$$

式中, $\tilde{N}=N_{e}$, 对于父系遗传 $\tilde{m}=m_{S}+m_{P}$ 或对于 母系遗传 $\tilde{m}=m_{s}(\mathrm{Hu}, 2000)$ 。相对于一个隔离的随 机交配群体, 虽然基因流有缩短平均溯祖时间的趋 势, 但群体结构的存在 $\left(G_{s t}>0\right)$ 仍进一步延长了谱 系平均溯祖时间 (对于 $\mathrm{cpDNA},>N_{e}$ )。

对于连续分布群体, 有限的基因扩散导致隐含 的群体结构也会延长样本的平均溯祖时间, 理论上, $n$ 个中性cpDNA基因样本在一个邻近群体内的 $E(T)$ 可近似为:

$$
E(T)=\sum_{t}\left(\begin{array}{l}
n \\
2
\end{array}\right) \frac{1}{2 N_{b}}\left(1-\left(\begin{array}{l}
n \\
2
\end{array}\right) \frac{1}{2 N_{b}} \sum_{i=1}^{t-1} \frac{1}{i}\right)
$$

式中, 邻近个体数 $N_{b}=2 \pi\left(\sigma_{s}^{2}+\sigma_{P}^{2}\right) d$ (父系遗传)或 $2 \pi \sigma_{S}^{2} d$ (母系遗传), $\sigma_{S}^{2}$ 和 $\sigma_{P}^{2}$ 为种子和花粉扩散方 差(根据亲本与花粉或种子迁移距离计算), $d$ 为二维 空间群体密度 $(\mathrm{Hu}, 2000)$ 。邻近个体数在一维空间上 有不同的计算公式(Wright, 1969)。

可以证明群体在连续或离散分布下, 父系遗传 方式的单倍体基因的平均溯祖时间 $E(T)$ 要比母系遗 传方式的单倍体基因的平均溯祖时间 $E(T)$ 短, 中性 核基因的平均溯祖时间 $E(T)$ 介于两者之间。上述结 论有助于深入理解群体结构对 cpDNA谱系系统进 化或谱系分选的影响。至今已有许多研究证实离散
群体结构下 $\mathrm{cpDNA}$ 与nDNA中性标记谱系地理进化 树不一致 (Schonswetter et al, 2007; Ikeda \& Setoguchi，2013), 反映了不同的溯祖进程，但在群 体连续分布下的例子报道很少。

自然选择会影响基因的谱系地理结构和溯祖 时间，理论上，适应性cpDNA基因标记与中性的非 编码区标记应表现出不同的谱系地理结构。至今比 较同一物种叶绿体DNA上中性和非中性区域谱系 地理的研究很少, 较多的报道分析自然选择怎样影 响nDNA 基因谱系地理结构 (Ikeda \& Setoguchi, 2009)。

对于单个群体, cpDNA突变率高的区域(LSC中 的非编码区标记)一般用于分析进化时间相对短的 种内基因谱系地理变异，而突变率低的区域(LSC、 SSC及IR区的功能基因标记)用于分析进化时间相 对长的基因谱系地理变异, 同一叶绿体DNA上的两 种标记可反映不同的谱系地理结构和溯祖过程。在 群体遗传结构存在的情况下 $\left(F_{s t} \neq 0\right)$, 高突变率 可增强群体遗传结构分化 $\left(1 / F_{s t}=1+4 N_{e}(m+u), m\right.$ 为迁移率, $u$ 为突变率; Wright, 1969), 从而增强基因 谱系地理结构和推迟基因溯祖进程, 如延长基因样 本的平均溯祖时间 $E(T)$ 。类似地, 至今比较 $\mathrm{cPDNA}$ 不同突变率区域的基因谱系地理变异的研究报道 很少(Vachon \& Freeland, 2011)。

由于细胞内cpDNA之间很少发生重组, 在不同 的进化动力(漂变、选择和迁移)作用下, 突变形成的 多态性“等位基因”可以被维持，因此叶绿体DNA可 逐渐累积不同的碱基突变。这些不同的突变碱基在 cpDNA上组合形成单倍型(同一染色体上具有统计 测定显著关联的多个SNP等位基因组成), 不同单倍 型在种间或种内个体间具有不同的年龄(从突变开 始到分析时，单倍型在谱系中存在的时间)。在实际 基因谱系地理分析中，结合群体结构与cpDNA单倍 型频率或碱基序列差异的空间分布，可应用基因溯 祖理论推测: (1)单倍型网络结构; (2)现有群体起源 和历史形成路径; (3)嵌套分支系统地理分析(nested clade phylogeographical analysis, NCPA)或嵌套分支 分析(NCA) (Templeton, 1998)。这方面的谱系地理 分析一直受到关注，已有大量的报道(Ekhvaia et al, 2018; Guo et al, 2018)。

从 cpDNA单倍型群体结构分析入手, 通过比较 单倍型频率和单倍型碱基序列差异在群体内和群 
体间的遗传多样性 $\left(N_{s t}, G_{s t}, h_{t}, h_{s}\right)$ 来检测谱系地理结 构变异是否存在, 这方面的研究有长足进展。以中 国的研究为例, Wu和Wu (1996)总结了三个植物亚 区(青藏高原植物亚区、中国-喜马拉雅森林植物亚 区及中国-日本森林植物亚区), 在此大框架内有系 列研究报道。Qiu等(2011)对青藏高原和中国-喜马 拉雅森林植物亚区内的现有植物群体遗传结构进 行了详细评述, 认为在第四纪冰期气候、地形及海 平面等变化影响下，一些物种的谱系地理模式支持 已有的3种生物地理或古生态学假设: (1)青藏高原 植物冰期后的重建是从东南面的冰期避难所开始; (2)中国西南地区群体隔离与濒危物种是由于地壳 及河道运动造成; (3)中国亚热带(中、东、南部)、温 带及暖温带地区, 植物群体和物种长期隔离和生存 于落叶林内局部避难所。但对青藏高原高寒草本和
森林植物在冰期时生存、温带常绿植物长期的避难 所隔离、中国北部温带和寒温带落叶林内隐秘避难 所存在，以及在中国东部-日本-韩国区域，不同谱 系异域-隔离的深度分化(在第四纪末/早至中更新 世)等问题存在争议。于海涁和张镱锂(2013)总结了 36种青藏高原亚区内的植物谱系地理模式，支持 Qiu等(2011)观点。近期Renner (2016)根据含有部分 植物cpDNA单倍型的谱系地理变异模式, 对青藏高 原隆升时间及可能的避难所进行了分析。表1列出 了在中文期刊上发表的相关论文及所推测的谱系 地理形成机制。以上这些结论为研究中国及东亚区 域其他植物谱系地理变异、生物多样性及遗传资源 保护提供了参考。

应用cpDNA全基因组序列可进一步推测不同 中性区域的突变影响(如比较cpDNA上非编码区

表1 基于cpDNA单倍型在群体内与群体间的变异检测谱系地理结构

Table 1 Testing phylogeographic structure based on the variation of cpDNA haplotypes within and among populations

\begin{tabular}{|c|c|c|c|}
\hline 物种 Species & $\begin{array}{l}\text { 主要谱系分析 } \\
\text { Main phylogeographic } \\
\text { analysis }\end{array}$ & $\begin{array}{l}\text { 谱系地理形成机制 } \\
\text { Mechanisms of forming phylogeographic structure }\end{array}$ & $\begin{array}{l}\text { 参考文献 } \\
\text { References }\end{array}$ \\
\hline 海仙报春 Primula poissonii & $N_{s t}>G_{s t}$ & 异域片断化 Allopatric fragmentation & Song et al, 2011 \\
\hline 绵参 Eriophyton wallichii & $N_{s t}=G_{s t}$ & $\begin{array}{l}\text { 无谱系结构、地形和环境及“孤岛效应”形成 } \\
\text { No phylogeographic structure due to the effects of } \\
\text { topography, environments and “isolated islands” of habitats }\end{array}$ & $\begin{array}{l}\text { Wang YZ et al, } \\
2011\end{array}$ \\
\hline $\begin{array}{l}\text { 蒙古绣线菊 } \\
\text { Spiraea mongolica }\end{array}$ & $N_{s t}>G_{s t}, N C A$ & $\begin{array}{l}\text { 第四纪冰期-间冰期气候动荡，青藏高原隆升的共同作用 } \\
\text { Joint effects of climate oscillation in Quaternary } \\
\text { glacial-interglacial periods and the rise of the Qinghai-Tibetan Plateau }\end{array}$ & $\begin{array}{l}\text { Wang JL et al, } \\
\text { 2014; } \\
\text { Zhang FQ et al, } \\
2012\end{array}$ \\
\hline 手参 Gymnadenia conopsea & $N_{s t}<G_{s t}$ & $\begin{array}{l}\text { 无谱系地理分化、群体未经历扩张 } \\
\text { Insignificant phylogeographic structure and no population expansion }\end{array}$ & Bao et al, 2016 \\
\hline $\begin{array}{l}\text { 肋果沙棘 } \\
\text { Hippophae neurocarpa }\end{array}$ & $N_{s t}>G_{s t}, N C A$ & $\begin{array}{l}\text { 避难所隔离分化及邻域扩张 } \\
\text { Allopatric isolation of refugia and contiguous range expansion }\end{array}$ & Meng et al, 2008 \\
\hline 远志 Polygala tenuifolia & $N_{s t}>G_{s t}$ & 地理隔离 Geographic isolation & Han et al, 2014 \\
\hline $\begin{array}{l}\text { 祁连圆柏 } \\
\text { Juniperus przewalskii }\end{array}$ & $G_{\text {st }}$ & $\begin{array}{l}\text { 多个避难所、瓶颈效应和奠基者效应 } \\
\text { Multiple refugia, bottleneck and founder effects }\end{array}$ & Zhang et al, 2005 \\
\hline 虎耳草 Saxifraga stolonifera & $N_{s t}=G_{s t}$ & $\begin{array}{l}\text { 无谱系地理结构、多个微型避难所、群体片断化 } \\
\text { No phylogeographic structure, multiple small refugia, } \\
\text { and population fragmentation }\end{array}$ & Gengji et al, 2018 \\
\hline $\begin{array}{l}\text { 半日花 } \\
\text { Helianthemum soongoricum }\end{array}$ & $N_{s t}>G_{s t}$ & 地理隔离 Geographic isolation & Han et al, 2017 \\
\hline 伯乐树 Bretschneidera sinensis & $G_{s t}$ & $\begin{array}{l}\text { 生境破碎化、地理隔离 } \\
\text { Habitat fragmentation and geographic isolation }\end{array}$ & $\begin{array}{l}\text { Wang MN, et al, } \\
2011\end{array}$ \\
\hline $\begin{array}{l}\text { 南方红豆杉 } \\
\text { Taxus wallichiana var. Mairei }\end{array}$ & $G_{s t}, N C A$ & $\begin{array}{l}\text { 弱谱系地理结构、片断化和隔离 } \\
\text { Weak phylogeographic structure, fragmentation and isolation }\end{array}$ & $\begin{array}{l}\text { Zhang XM, et al, } \\
2012\end{array}$ \\
\hline
\end{tabular}

$N_{s t}$ : 根据单倍型碱基序列差异在群体内和群体间的分布估计的群体遗传分化系数; $G_{s t}$ : 根据单倍型的频率在群体间的分布估计的群体遗传 分化系数; NCA: 嵌套分支分析。

$N_{s t}$, Population differentiation coefficient estimated from the distribution of DNA base sequence differences among cpDNA haplotypes within and among populations; $G_{s t}$, Population differentiation coefficient estimated from the distribution of cpDNA haplotype frequencies among populations; NCA, Nested clade analysis. 
与编码区的 $F_{s t}$ 分布模式)和遗传搭乘效应或背景选 择效应的定位(Hu \& He, 2005), 更精细地分析基因 组结构、群体遗传结构、谱系地理分布及进化关系。 随着高通量测序技术的应用, 今后cpDNA全基因组 序列的谱系地理研究会日益增加。

\section{3 杂交带与基因渐渗}

在前面讨论的群体遗传结构中, 基因分布与地 理位置的关系是不明确的。有一种特定的群体遗传 结构是基因频率随空间地理距离表现出梯度变化 (cline), 基因分布与地理距离有明确的关系模式。这 种地理变异模式常发生在杂交带, 当两个遗传分化 的群体或种迁移到同一个地理区域时会产生杂交 个体，例如，冰期后两个避难所群体沿相逆方向扩 张发生二次接触(secondary contact)时形成杂交带, 杂交个体形成后，基因通过回交方式从一个物种/ 群体渐渗到另一个物种/群体的基因组中。由于多数 物种不同程度地存在自然杂交, 杂交带现象在谱系 地理变异研究中占有一定位置。cpDNA标记在杂交 带研究的应用主要体现在3个方面: 杂交个体识别、 基因流推测及基因渐渗评价。

在自然杂交带, 杂交个体识别是研究这一地理 变异模式的一个基本环节。可根据cpDNA单亲遗 传、基因组无重组及细胞核质不平衡(cytonuclear linkage disequilibrium)特点来确定杂交个体。例如, 根据山松复合体 (Pinus montezumae complex) cpDNA的父系遗传及其单倍型多态性在种间的分 布推测杂交种的存在(Matos \& Schaal, 2010)。若 nDNA与 与pDNA或mtDNA来自不同物种, 该个体可 视为杂交个体(Renoult et al, 2009)。这方面已有许多 报道, 例如, 张辉(2005) ${ }^{\circledR}$ 利用沙棘属(Hippophae)植 物母系遗传的叶绿体基因组(trnL-F和trnS-G序列)和 核基因组标记(ncpGS序列), 研究了包括中国沙棘 (H. rhamnoides subsp. sinensis) 和肋果沙棘 (H. neurocarpa subsp. neurocarpa) 在内的沙棘属6个物 种10个类群，根据核质基因树的不一致性和杂交个 体在基因树上的分支行为两种方法检验棱果沙棘 (H. goniocarpa subsp. goniocarpa)的杂交起源, 并揭 示青海祁连棱果沙棘自然群体建立过程中基因渗

(1) 张辉 (2005) 棱果沙棘的同倍体杂交起源: 来自叶绿体基因组 和核基因组的证据. 硕士学位论文, 西北师范大学, 兰州.
入的方向。王芗等(2015)用单拷贝核DNA序列 $C R Y 2$ exon3和叶绿体DNA序列 $r b c \mathrm{~L} 、 a t p \mathrm{~A} 、 a t p \mathrm{~B}$ 、 $t r n L-F 、 r p s 4-t r n S$ 等鉴定云南元江产梅山铁线偋( $A d-$ iantum meishanianum) 存疑种, 证明其为以苍山铁 线蕨 (A. sinicum) 为母本、孟连铁线蕨 (A. menglianense)为父本的自然杂交种。Meirmans等(2017)利用 93 个nDNA和17个 $\mathrm{cpDNA}$ 单核苷酸位点多态性标记 识别大叶钻天杨(Populus balsamifera)与毛果杨 ( $P$. trichocarpa)两物种杂合子及二次接触的杂交带, 并 发现在大叶钻天杨自然分布中, 东西部地理分布区 的基因频率有不同的梯度变化模式。

实际应用时, 少部分被子植物的cpDNA也有双 亲遗传的(Barnard-Kubow et al, 2017)。在针叶树中, cpDNA单亲遗传方式也可能具母系遗传或双亲遗 传现象, 导致原来的父系或母系遗传方式在少数个 体中出现母系/父系遗传, 如欧洲山松(Pinus mugo) 的cpDNA呈现母系遗传(Kormutak et al, 2018), 这 时需要结合cpDNA、mtDNA及nDNA三种DNA标记 同时判断杂合性。

从一个物种/群体到杂交带再到另一个物种/群 体的空间变化过程中, 若cpDNA标记是中性，基因 频率在空间上会暂时呈现渐变式的变化, 这种渐变 模式随时间推移而消失，漂变只是使得渐变模式波 动或延长基因扩散时间，但不会改变中性基因穿越 杂交带的结果。在同质的生境条件下，母系遗传方 式(种子流)比父系遗传方式(种子和花粉流)的 cpDNA基因频率渐变模式维持时间要长, 但都会成 功跨越杂交带进行扩散(Barton \& Gale, 1993), 因此 理论上可预期群体间/种间 cpDNA非编码区中(如 LSC区的内含子片段或可能的SSR)差异很小, 群体 间遗传分化小(Ramos-Ortiz et al, 2016)。

花粉和种子流可导致细胞核质基因连锁不平 衡(cytonuclear linkage disequilibrium), 在杂交中心 区域表现最强。若核基因为适应性基因时，在选择一 迁移作用下，核基因频率会呈现稳定的渐变模式。 核质连锁不平衡变化可使得 cpDNA中性位点基因 频率产生相对稳定的渐变模式(尽管中性基因最终 会渐渗穿越过杂交带), 理论上该结果在与环境无 关的杂交带(tension zone, 由遗传背景差异导致杂 合子适应性弱)或在与环境有关的生态杂交带 (ecological zone, 环境选择导致杂合子适应性弱)都 
会出现(Hu, 2008)。虽然这两类杂交带从基因频率的 渐变模式上难以区分, 但可用基因连锁不平衡值的 空间变化特点加以区别(Hu, 2005)。此外, 在生态杂 交带, 即使核基因扩散存在对称的物理障碍, 核质 连锁不平衡也可导致父系或母系遗传的cpDNA中 性基因扩散产生非对称的障碍，因此在用cpDNA中 性标记分析时应注意解析这些差异, 有关结论尚待 验证。

对于适应性的cpDNA位点, 如Bock等(2014)报 道的案例, 迁移一自然选择联合作用可产生稳定的 基因频率渐变模式, 其父系遗传方式的基因频率渐 变的特征长度(基因频率稳定不变的地理长度或范 围)为:

$$
l_{\text {paternal }}=\tilde{\sigma} / \sqrt{s}
$$

式中, $\tilde{\sigma}^{2}=\sigma_{S}^{2}+\sigma_{P}^{2}, \sigma_{S}^{2}$ 和 $\sigma_{P}^{2}$ 依次为种子和花粉 扩散方差, $s$ 为选择系数。母系遗传方式的基因频率 渐变的特征长度为:

$$
l_{\text {maternal }}=\sigma_{S} / \sqrt{s}
$$

而核基因频率渐变的特征长度为:

$$
l_{\text {biparental }}=\tilde{\sigma} / \sqrt{s}
$$

式中, $\tilde{\sigma}^{2}=\sigma_{S}^{2}+\sigma_{P}^{2} / 2(\mathrm{Hu} \& \mathrm{Li}, 2002)$ 。cpDNA与 nDNA适应性基因在杂交带的扩散速度和渐渗程度 不一致, 核质基因连锁不平衡进一步限制了 $\mathrm{cpDNA}$ 基因的渐渗。至今已有许多以动物为材料的研究证 明同一杂交带内种间/群体间核质基因交换/渐渗存 在不一致现象(Arntzen et al, 2017), 但在植物杂交 带的研究报道相对较少(Young, 1996; Watano et al, 2004)。适应性基因渐渗不一致间接地反映了迁移自然选择的联合作用在维持种间/群体间核质基因 组群体遗传分化上的差异。

中国近二十年在以cpDNA为标记研究植物种 间基因渐渗方面有快速发展，植物种类包括木本、 藤本、灌木等。例如, 张田等(2006)利用猕猴桃属 (Actinidia)植物的cpSSR标记分析表明中华/美味狝 猴桃复合体(A. chinensis/A. deliciosa complex)近缘 种间存在明显的共祖多态性和杂交渐渗现象。Zeng 等(2012)利用核微卫星标记和cpDNA序列分析了新 疆阿勒泰地区额尔齐斯河流域银白杨(Populus alba) 和欧洲山杨 (P. tremula)杂交带的基因渐渗。类似的 研究还有Bai等(2014)的野核桃(Juglans cathayensis)
系统地理学研究, 及Sun等(2014)有关青藏高原的 紫果云杉(Picea purpurea)起源主要途径的研究。应 用 $c p D N A$ 条形码 $(m a t \mathrm{~K}, r p o \mathrm{C} 1, r p o \mathrm{~B}, a c c \mathrm{D}, n h d \mathrm{~J}$, $Y C F 5$ 等)鉴定物种及种间渐渗已有许多报道(CBOL Plant Working Group, 2009), 这里就不详细阐述。

估算杂交带基因流对于深入理解基因渐渗程 度、评价和研究cpDNA转基因逃逸与环境风险等问 题有重要实际意义(卢宝荣等, 2009; Hu, 2011)。至今 基因流的间接估算方法已有许多报道，如基于基因 频率和DNA序列的计算方法(表2)。这些方法根据中 性标记和不同的模型假设建立，可以用于估计杂交 带群体间的基因流。例如，从跨越杂交带多群体抽 样，根据cpDNA标记在多群体的基因型/基因频率 变化, 计算 $F_{s t}$ 并估计群体间基因流, 这方面已有大 量研究报道, 但其前提是假设群体漂变-迁移达到 平衡。另一种基于杂交带多群体的估计方法就是直 接根据基因型/基因频率建立似然函数来估算迁移 率，该种方法有待完善。大量的研究证明cpDNA中 性标记在种内群体间的遗传分化要比nDNA中性标 记的大, 这主要与cpDNA的单亲遗传和单倍性有关, 该结论在杂交带群体间分化研究中也同样成立 (Meirmans et al, 2017)。与nDNA标记联合应用时, 可估计花粉和种子流对基因流的相对贡献及评价 杂交带维持机制, 这方面研究同样有许多报道 (Zhang et al, 2017)。若采用多群体cpDNA序列样本,

\section{表2 基因流间接估算模型与方法}

Table 2 Models and methods for indirect estimation of gene flow

\begin{tabular}{ll}
\hline 模型 & $\begin{array}{l}\text { 参考文献 } \\
\text { References }\end{array}$ \\
\hline 基因频率 & \\
Gene frequency & \\
$\quad F_{s t}$ (岛屿模型) & Wright, 1969 \\
$F_{\text {st }}$ (Island model) & \\
基于私有基因途径 & Barton \& Slatkin, \\
Private allele & 1986 \\
$\quad$ 极大似然估计 & Slatkin \& Barton, \\
Maximum likelihood estimate & 1989 \\
DNA序列 & \\
DNA sequence & \\
$F_{s t}$ 基因树途径) & \\
$F_{\text {st }}$ (gene tree approach) & Hudson et al, 1992 \\
隔离-迁移模型 & \\
Isolation-with-migration (IM) model & Hey \& Nielsen, 2007; \\
$\quad$ 起始隔离-迁移模型 & Wang \& Hey, 2010 \\
Initial-isolation-with-migration (IIM) model & Herbots, 2017 \\
\hline
\end{tabular}


也有报道检测基因迁移率(Ge et al, 2015)。需要注意 的是如果仅用 $\mathrm{cpDNA}$ 序列检测种间基因流的话，由 于 cpDNA为单倍体, 无重组且单亲遗传, 所检测到 的基因流理论上应该指物种分化前发生的基因交 换或分化后物种 $\mathrm{cpDNA}$ 的截获概率(organelle genome capture)(Bock et al, 2014), 怎样解析基于cpDNA序列 所估计的种间基因流有待进一步探讨, 至今更多的 研究是根据nDNA序列或经过长期适应分化的基因 组序列来估计种间基因交换(Hu \& Filatov, 2016)。

\section{4 谱系分选与物种形成}

当种内群体遗传结构分化到一定程度时, 高度 分化的群体在进化驱动作用下向新物种形成 (incipient speciation)阶段发展, 最终成为新物种。例 如, 起先的一个群体分裂成两个后裔群体时, 在无 基因流的情况下, 后裔群体通过进化动力作用(漂 变、突变和选择)逐渐分化形成新的物种, 这一过程 即通常所指的谱系分选过程(Avise, 2000)。从谱系的 遗传亲缘关系变化看, 分选过程由起初的复系(polyphyly, 一个群体或物种不都共有相同的新近祖先) 到并系(paraphyly，一个群体或物种包含一些但不 是全部的一个新近祖先的后裔)再到单系(monophyly, 一个群体或物种全部共有一个祖先, 并且这 个祖先的所有后裔在该群体或物种中都可以找 到)(Freeland et al, 2011)。整个分选过程涉及到从微 观进化沿着群体适应值(population fitness)分化转移 到宏观进化过程。单系或新物种形成后, 各群体达 到不同的适应峰值(Wright, 1977; Gavrilets, 2004), 因此单系阶段物种基因组间差异趋于极大，趋于固 定不同的适应性等位基因。

cpDNA标记在评价谱系分选进程研究中起着 重要作用。已知的溯祖理论证明对于一个隔离群体, 在漂变过程中, 从复系到单系平均需要 $4 N_{e}$ 世代 (nDNA) (Tajima，1983)或 $N_{e}$ 世代(单倍体cpDNA或 mtDNA), cpDNA单系形成要比nDNA单系形成早 $3 N_{e}$ 世代(Palumbi et al, 2001)。Hudson和Coyne (2002) 进一步发现要达到 $50 \%$ 的核基因单系需要 $4-7 N_{e}$ 世 代, 95\%的核基因单系需要9-12 $N_{e}$ 世代, 他们建议 不用mtDNA或cpDNA识别群体长期分化后的谱系 物种(genealogical species)。Rosenberg (2003)更具体 地证明, 在中性的谱系分选过程中, 复系维持的概 率随时间逐渐下降, 并系形成的概率开始略微升高
然后再下降，而单系形成的概率由小逐渐升高并趋 于固定，与Tajima (1983)分析DNA序列进化关系的 结论类似。这些中性过程下的结论可作为无效假设 来测定其他非中性过程是否存在 (Palumbi et al, 2001), 但其随后的应用研究很少。

在新物种形成过程中，一般认为漂变效应对物 种形成贡献不大(Coyne \& Orr, 2004)。因此除突变过 程外，基因流和自然选择在物种形成过程中是两个 重要且相互作用的过程: 当选择强度高于基因流时, 即使基因流存在，物种形成仍然在进行; 但当基因 流超过一定的阈值时，基因流可淹没(swamping)局 域适应性等位基因，导致新物种形成概率下降。核 基因和叶绿体基因有不同的基因流阈值( $\mathrm{Hu}, 2011)$, 因而存在不同的谱系分选进程。注意这里讨论的基 因流是与物种分选过程相关的适应性基因交换，种 间中性基因流仍不受影响或受弱选择(与适应性基 因紧密连锁时)影响。关于基因流与物种形成的关系, 刘义飞和黄宏文(2009)及李忠虎等(2014)有详细 综述。

除漂变过程产生nDNA和cpDNA单系形成时间 差异外，分裂选择(disruptive selection，选择有利于 2 个或多个极端表型个体，比表型值位于中间的个 体有更高的适应值)可增强nDNA或cpDNA适应性 基因的分化(如适应辐射形成不同的生态新种 (ecological speciation)), 从而改变中性条件下期望 的单系形成时间差异, 有可能导致不完全的谱系分 选，这方面以动物为材料的研究中已有较多的报道 支持 $\mathrm{nDNA}$ 和mtDNA单系形成进程差异(Brown et al, 2010), 但在植物谱系分选差异方面报道少。

同样，基因重组或种间杂交导致同一染色体上 的不同区域来源于不同祖先，形成网状进化(reticulated evolution)模式, 改变单系形成过程, 这对 nDNA影响较大, 对cpDNA影响较小(几乎无重组发 生), 但有害突变的累积在cpDNA上更为严重, 选 择将导致cpDNA快速进化。不同的基因流载体也是 导致nDNA (种子和花粉流)和cpDNA (母系遗传:种 子流; 父系遗传:种子和花粉流)单系进程差异的原 因之一。当中性区域或中性标记与适应基因连锁时， 连锁不平衡也可改变纯中性条件下期望的单系形 成时间差异。此外, 交配系统作用过程复杂, 可通 过与基本进化动力互作, 如改变有效群体 $N_{e}$ 及核质 基因的选择功效(Hu, 2011)，阻碍群体间基因流(Hu, 
2015), 改变单系形成时间, 这些理论预测尚待实际 验证。以上分析说明不同的进化过程可改变cpDNA 的单系形成及其与nDNA单系形成的进程差异。

至今已有大量的研究同时采用 $c p D N A$ 和nDNA 标记进行谱系分选分析, 界定物种或确定物种分类 地位。理论上，根据nDNA或表型值与cpDNA谱系 分选进程可产生 9 种不同组合(表3), 核质基因组揭 示谱系分选进程一致的有3种, 不一致的有6种。已 有的文献显示, nDNA谱系分选分析多数采用ITS或 ITS1-5.8S-ITS2 (非编码区域)作标记, cpDNA谱系 分选研究多数采用非编码区域作标记, 少数用功能 基因序列作标记(如 $m a t \mathrm{~K}$ 与 $r b c \mathrm{~L}$ 基因)。核质基因组 谱系分选进程一致的研究报道较多(表3), 可能是在 测定时核质基因组都早已进入单系阶段。核质基因 组谱系分选进程不一致的研究报道少, 可能的原因 是nDNA需要更长时间到达单系, 但由于 $\mathrm{cpDNA}$ 单 位点平均突变率比nDNA或动物mtDNA的单位点突 变率要低, 因此用相对高突变率的nDNA中性标记
与低突变率 $c p D N A$ 标记时在到达单系阶段的时间 差异小，或产生一致的复系和并系。中性或近中性 标记的应用排除了自然选择的干扰，理论上核质基 因谱系分选进程不一致的可能性更大，应该有更多 报道。在动物谱系分选进程分析时, Funk和Omland (2003)调查了 2,319种，估计出23\%的并系或复系， 但对于nDNA与mtDNA基因组谱系分选差异没作具 体分析。

联系到谱系地理变异, 群体空间分布和遗传结 构与核质谱系分选过程有重要关系, 尤其是在复系 阶段。物种地理分布与新物种形成有复杂的关系 (Nosil, 2012)。虽然物种形成不一定需要地理隔离, 如同域物种形成(sympatric speciation, 一个群体在 无地理障碍下分裂成两个或多个生殖隔离物种), 但地理障碍(山脉，河流等)可以弱化群体间的 nDNA和cpDNA基因流，如地理分隔(vicariance)产 生不同的自然生境和自然选择系统, 促进新物种 形成。在物种分布特征长度 $l=\tilde{\sigma} / \sqrt{s}$ （ $\tilde{\sigma}$ 为基因

表3 cpDNA和nDNA谱系分选进程比较及可能的进化过程

Table 3 Comparison of lineage sorting phases between cpDNA and nDNA and the possible evolutionary processes

\begin{tabular}{|c|c|c|c|c|c|c|}
\hline $\begin{array}{l}\text { nDNA/表型 } \\
\text { 性状 nDNA/ } \\
\text { Phenotypic } \\
\text { traits }\end{array}$ & cpDNA & $\begin{array}{l}\text { 可能的进化过程 } \\
\text { Possible evolutionary processes }\end{array}$ & $\begin{array}{l}\text { nDNA标记 } \\
\text { nDNA markers }\end{array}$ & $\begin{array}{l}\text { cpDNA标记 } \\
\text { cpDNA markers }\end{array}$ & $\begin{array}{l}\text { 分类群 } \\
\text { Taxonomic groups }\end{array}$ & $\begin{array}{l}\text { 参考文献 } \\
\text { References }\end{array}$ \\
\hline \multirow[t]{9}{*}{$\begin{array}{l}\text { 复系 } \\
\text { Polyphyly }\end{array}$} & \multirow[t]{7}{*}{$\begin{array}{l}\text { 复系 } \\
\text { Polyphyly }\end{array}$} & \multirow{7}{*}{$\begin{array}{l}\text { 物种形成初期, nDNA和cpDNA均以漂 } \\
\text { 变过程为主 } \\
\text { Lineage sorting is mainly driven by drift } \\
\text { process for both nDNA and cpDNA in the } \\
\text { incipient stage of speciation. }\end{array}$} & \multirow[t]{2}{*}{ LBD6 } & matK, trnD-T & $\begin{array}{l}\text { 葛藤属(豆科) } \\
\text { Pueraria (Leguminosae) }\end{array}$ & $\begin{array}{l}\text { Egan et al, } \\
2016\end{array}$ \\
\hline & & & & trnK intron, trnL-F & $\begin{array}{l}\text { 姜味草属(唇形科) } \\
\text { Micromeria (Lamiaceae) }\end{array}$ & $\begin{array}{l}\text { Brauchler et } \\
\text { al, } 2005\end{array}$ \\
\hline & & & ITS1-5.8S-ITS2 & $\operatorname{trnL}-\mathrm{F}, \operatorname{trn\mathrm {D}}-\mathrm{T}$ & $\begin{array}{l}\text { 长铮蘚属(青蘚科) } \\
\text { Rhynchostegium } \\
\text { (Brachytheciaceae) }\end{array}$ & $\begin{array}{l}\text { Huttunen \& } \\
\text { Ignatov, } 2010\end{array}$ \\
\hline & & & ITS & $a t p \mathrm{~B}-r b c \mathrm{~L}$ & $\begin{array}{l}\text { 丁香蓼属(柳叶菜科) } \\
\text { Ludwigia (Onagraceae) }\end{array}$ & $\begin{array}{l}\text { Hung et al, } \\
2009\end{array}$ \\
\hline & & & $\begin{array}{l}\text { ITS, 表型 } \\
\text { Phenotype }\end{array}$ & $\operatorname{trnL-F}$ & 唇柱苣苔属 Chirita & $\begin{array}{l}\text { Wang YZ, et } \\
\text { al, } 2011\end{array}$ \\
\hline & & & ITS & $\operatorname{trnT}-\mathrm{L}$ & $\begin{array}{l}\text { 火把莲属(独尾草科) } \\
\text { Kniphofia (Asphodelaceae) }\end{array}$ & $\begin{array}{l}\text { Ramdhani et } \\
\text { al, } 2009\end{array}$ \\
\hline & & & ITS & trnL-F, psbA-trnH & $\begin{array}{l}\text { 瓦苇属(独尾草科) } \\
\text { Haworthia (Asphodelaceae) }\end{array}$ & $\begin{array}{l}\text { Ramdhani et } \\
\text { al, } 2011\end{array}$ \\
\hline & $\begin{array}{l}\text { 并系 } \\
\text { Paraphyly }\end{array}$ & $\begin{array}{l}\text { cpDNA以漂变或自然选择过程为主; } \\
\text { nDNA存在杂交或渐渗过程 } \\
\text { Lineage sorting is mainly driven by drift } \\
\text { or selection process for cpDNA but by } \\
\text { hybridization or introgression process for } \\
\text { nDNA. }\end{array}$ & - & - & - & - \\
\hline & $\begin{array}{l}\text { 单系 } \\
\text { Monophyly }\end{array}$ & $\begin{array}{l}\text { cpDNA以漂变或自然选择为主; nDNA } \\
\text { 存在杂交或渐渗过程 } \\
\text { Lineage sorting is mainly driven by drift } \\
\text { or selection process for cpDNA but by } \\
\text { hybridization or introgression process for } \\
\text { nDNA. }\end{array}$ & - & - & - & - \\
\hline
\end{tabular}




\begin{tabular}{|c|c|c|c|c|c|c|}
\hline \multicolumn{2}{|c|}{$\begin{array}{l}\text { nDNA/表型cpDNA } \\
\text { 性状 } \\
\text { nDNA/ } \\
\text { Phenotypic } \\
\text { traits }\end{array}$} & $\begin{array}{l}\text { 可能的进化过程 } \\
\text { Possible evolutionary processes }\end{array}$ & $\begin{array}{l}\text { nDNA标记 } \\
\text { nDNA markers }\end{array}$ & $\begin{array}{l}\text { cpDNA标记 } \\
\text { cpDNA markers }\end{array}$ & $\begin{array}{l}\text { 分类群 } \\
\text { Taxonomic groups }\end{array}$ & $\begin{array}{l}\text { 参考文献 } \\
\text { References }\end{array}$ \\
\hline \multirow[t]{5}{*}{$\begin{array}{l}\text { 并系 } \\
\text { Paraphyly }\end{array}$} & $\begin{array}{l}\text { 复系 } \\
\text { Polyphyly }\end{array}$ & $\begin{array}{l}\text { nDNA以自然选择过程为主; cpDNA存在 } \\
\text { 渐渗过程 } \\
\text { Lineage sorting is mainly driven by } \\
\text { selection process for nDNA but by } \\
\text { introgression process for cpDNA. }\end{array}$ & - & - & - & - \\
\hline & \multirow[t]{3}{*}{$\begin{array}{l}\text { 并系 } \\
\text { Paraphyly }\end{array}$} & \multirow[t]{3}{*}{$\begin{array}{l}\text { nDNA和cpDNA均以漂变过程为主, 或存 } \\
\text { 在渐渗/基因流过程 } \\
\text { Lineage sorting is mainly driven by drift } \\
\text { process or introgression/gene flow process } \\
\text { for both nDNA and cpDNA. }\end{array}$} & ITS, ETS & $\begin{array}{l}\operatorname{trnQ}-r p s 16, \\
\text { rpl32-trnL, } r p s 16, \\
\text { trnS-G, trnH-psbA }\end{array}$ & $\begin{array}{l}\text { 可草拟库氏金鱼花 } \\
\text { (苦苍苔科) } \\
\text { Columnea kucyniakii } \\
\text { (Gesneriaceae) }\end{array}$ & $\begin{array}{l}\text { Smith et al, } \\
2018\end{array}$ \\
\hline & & & $\begin{array}{l}\text { 卫星DNA } \\
\text { Microsatellites } \\
\text { DNA }\end{array}$ & atpL-H, rps16-trnK & $\begin{array}{l}\text { 穗花杉(红豆杉科) } \\
\text { Amentotaxus argotaenia } \\
\text { (Taxaceae) }\end{array}$ & $\begin{array}{l}\text { Ge et al, } \\
2015\end{array}$ \\
\hline & & & ITS & $m a t \mathrm{~K}, r b c \mathrm{~L}$ & $\begin{array}{l}\text { 松属单维管束松亚属(松科) } \\
\text { Pinus subgenus Strobus } \\
\text { (Pinaceae) }\end{array}$ & $\begin{array}{l}\text { Sying et al, } \\
2007 \text {; } \\
\text { Gernandt et } \\
\text { al, } 2005\end{array}$ \\
\hline & $\begin{array}{l}\text { 单系 } \\
\text { Monophyly }\end{array}$ & $\begin{array}{l}\text { cpDNA以漂变或自然选择过程为主 } \\
\text { Lineage sorting for cpDNA is mainly } \\
\text { driven by drift or selection process. }\end{array}$ & - & - & & \\
\hline \multirow[t]{8}{*}{$\begin{array}{l}\text { 单系 } \\
\text { Monophyly }\end{array}$} & $\begin{array}{l}\text { 复系 } \\
\text { Polyphyly }\end{array}$ & $\begin{array}{l}\text { nDNA以自然选择过程为主; cpDNA以漂 } \\
\text { 变过程为主或存在渐渗过程 } \\
\text { Lineage sorting is mainly driven by } \\
\text { selection process for nDNA but by drift or } \\
\text { introgression process for cpDNA. }\end{array}$ & ITS & $\operatorname{trnL-F}, r p l 16$ & $\begin{array}{l}\text { 克非亚草属(千屈菜科) } \\
\text { Cuphea (Lythraceae) }\end{array}$ & $\begin{array}{l}\text { Barber et al, } \\
2010\end{array}$ \\
\hline & $\begin{array}{l}\text { 并系 } \\
\text { Paraphyly }\end{array}$ & $\begin{array}{l}\text { nDNA以自然选择过程为主; cpDNA以漂 } \\
\text { 变过程为主, 或存在渐渗过程 } \\
\text { Lineage sorting is mainly driven by } \\
\text { selection process for nDNA but by drift or } \\
\text { introgression process for cpDNA. }\end{array}$ & - & - & - & \\
\hline & \multirow[t]{6}{*}{$\begin{array}{l}\text { 单系 } \\
\text { Monophyly }\end{array}$} & \multirow{6}{*}{$\begin{array}{l}\text { nDNA和cpDNA均以漂变过程为主, 或均 } \\
\text { 存在自然选择过程 } \\
\text { Lineage sorting for both nDNA and cpDNA } \\
\text { is mainly driven by drift or selection } \\
\text { process. }\end{array}$} & $\begin{array}{l}\text { ITS, 表型 } \\
\text { ITS, phenotype }\end{array}$ & $\operatorname{trnT} \mathrm{T}-\mathrm{L}$ & $\begin{array}{l}\text { 常春藤(五加科) } \\
\text { Hedera (Araliaceae) }\end{array}$ & $\begin{array}{l}\text { Valcarcel et } \\
\text { al, } 2003\end{array}$ \\
\hline & & & 表型 Phenotype & $r b c \mathrm{~L}, n d h \mathrm{~F}$ & 柳叶菜科 Onagraceae & $\begin{array}{l}\text { Levin et al, } \\
2003\end{array}$ \\
\hline & & & ITS & $\begin{array}{l}\text { matK, } \operatorname{trn} \mathrm{L}, \operatorname{trn} \mathrm{L}-\mathrm{F}, \\
\text { trnS-G, } \operatorname{trn} \mathrm{D}-\mathrm{T} \\
\text { psbM-trn } \mathrm{D}\end{array}$ & 花葱科 Polemoniaceae & $\begin{array}{l}\text { Johnson et al, } \\
2008\end{array}$ \\
\hline & & & 表型 Phenotype & $\begin{array}{l}r b c \mathrm{~L}, r p s 16 \\
a t p \mathrm{~B}-r b c \mathrm{~L}\end{array}$ & $\begin{array}{l}\text { 茜草属(茜草科) } \\
\text { Kelloggiatorrey (Rubiaceae) }\end{array}$ & $\begin{array}{l}\text { Nie et al, } \\
2005\end{array}$ \\
\hline & & & ITS & $\begin{array}{l}\text { rbcL, trnL-F, } \\
\text { trnK-matK, } \\
\text { psbA-trnH }\end{array}$ & $\begin{array}{l}\text { 春蓼属(蓼科) } \\
\text { Persicaria (Polygonaceae) }\end{array}$ & $\begin{array}{l}\text { Kim \& } \\
\text { Donoghue, } \\
2008\end{array}$ \\
\hline & & & ITS1-5.8S-ITS2 & $\operatorname{trnL}-\mathrm{F}$ & $\begin{array}{l}\text { 红杉花属(花荵科) } \\
\text { Ipomopsis (Polemoniaceae) }\end{array}$ & $\begin{array}{l}\text { Porter et al, } \\
2010\end{array}$ \\
\hline
\end{tabular}

扩散方差平方根, $s$ 为选择系数)之外, 如一些边缘 群体, 自然选择或突变在复系和并系阶段有重要作 用(Funk \& Omland, 2003), 对邻域(parapatric speciation, 在基因流存在的条件下，一个空间分布很广 的群体内形成新物种)或异域物种形成(allopatric speciation, 由于地理隔离导致群体分化并形成生殖 隔离物种)起作用。在同域物种形成过程中, 分裂选 择, 如降低核基因杂合子的适应值或提高纯合子的 适应值, 或对叶绿体不同等位基因产生差异选择,
产生不同分离的后代群体。由于nDNA和cpDNA改 变程度和速度不一致, 它们在整个谱系分选过程中 形成单系时间不一致的概率大。

Wen等(2014)综述了中国青藏高原植物亚区的 植物多元化形成过程, 认为多种机制促使物种形成, 如通过地理隔离、气候循环运动与分化、传粉载体 隔离、杂交与渐渗及多倍化途径导致异域物种形成, 涉及的物种有马先蒿属(Pedicularis)、云木香(Saussurea)、杜鹃花(Rhododendron)、樱草属(Primula)、 
绿线蒿属(Meconopsis)、红景天属(Rhodiola)及一些 裸子植物。所列的有关研究应用cpDNA和nDNA或 仅用 cpDNA标记分析谱系结构的植物种都已处于 单系阶段, 不完全谱系分选的植物种研究有待报道 (Wen et al, 2014)。青藏高原植物生态辐射(ecological radiation)或适应性辐射(adaptive radiation)与青藏高 原隆起与冰期-间冰期气候变化等提供的多样化生 态位有关(Wellborn \& Langerhans, 2015), 漂变和分 裂选择可能是两个重要过程。

实际分析时需要注意到基因树与物种树的差 异(Degnan \& Rosenberg, 2006), 用cpDNA与nDNA 标记构建的系统树可以不一致(Renoult et al, 2009), 同样, 用 $c p D N A$ 非编码区域或中性标记构建系统进 化树与物种系统进化树可能也会有偏差。此外, 需 注意一些cpDNA基因转移到核基因组上(Stegemann et al, 2003), 使用cpDNA引物从整个混合基因组进 行PCR扩增时, PCR产物有可能来自核质基因组两 部分, 从而影响谱系分选结论 (Funk \& Omland, 2003), 这点在应用叶绿体DNA标记的谱系地理变 异中报道很少。随着高通量测序技术的应用, 用 cpDNA全基因组序列分析谱系地理变异成为可能, 上述两种错误概率可以降至最低, 如用 $70 \%$ 以上的 序列变异位点来进行谱系分选分析就有可能产生 稳定的结果，从而提高基于基因组序列谱系分选与 物种系统树的一致性。

\section{展望}

叶绿体基因组在组织结构、遗传方式、突变率、 基因流载体及有效群体数等方面与核及线粒体基 因组有显著的差异, 这些差异决定了应用叶绿体 DNA 分子标记与应用nDNA或mtDNA标记分析谱 系地理变异时可能得到不同的结果。已有的数据证 明叶绿体DNA标记在谱系地理研究中占有重要地 位。本文分析了这些特征是怎样影响分子标记的选 择, 扩大或缩小种内群体遗传结构分化, 延长或缩 短空间基因溯祖时间，促进或阻碍种间基因渐渗及 谱系分选(复系、并系和单系形成)进程。本文着重 阐述了这些影响的理论基础, 并分析了叶绿体分子 标记在这些方面的应用研究进展。至今的实际研究 在验证谱系地理变异理论模型方面相对滞后。

虽然细胞内 cpDNA间无重组, 不同 cpDNA区 域的谱系地理变异有可能存在异质性, 主要原因可
概括为以下三点：(1)编码与非编码区突变率不同, 可导致不同区域的群体遗传结构不同 $(\mathrm{Hu}$ et al, 2017); (2)中性区域与功能基因区域因自然选择强 度不同，可导致不同区域等位基因在群体中的固定 概率和群体间的分化不同; (3)有害突变基因与漂变 的联合作用可导致有害等位基因在不同群体中的 固定概率出现差异。此外，因核质互作影响, cpDNA 某些区域基因与核基因存在共同的父系或母系遗 传方式(Wolf，2009)，从而制约cpDNA特定区的突 变和选择。

今后一个研究重点就是应用叶绿体全基因组 序列样本研究谱系地理变异。Cutter (2013)阐述了有 关分析方法，这里我们建议分析DNA不同区域基因 渐渗程度差异分布, 并结合核DNA标记谱系变异结 果揭示谱系分选进程等, 在基因组水平上解析谱系 地理变异沿着叶绿体DNA序列变化特点, 深入理解 形成物种谱系地理结构的生态与进化过程。

\section{参考文献}

Arntzen J, Vries W, Canestrelli D, Martinez-Solano I (2017) Hybrid zone formation and contrasting outcomes of secondary contact over transects in common toads. Molecular Ecology, 26, 5663-5675.

Avise JC (2000) Phylogeography: The History and Formation of Species. Harvard University Press, Cambridge, Massachusetts.

Avise JC, Arnold J, Ball RM, Bermingham E, Lamb T, Neigel JE, Reeb CA, Sauders NC (1987) Intraspecific phylogeography: The mitochondrial DNA bridge between population genetics and systematics. Annual Review of Ecology and Systematics, 18, 489-522.

Bai WN, Wang WT, Zhang DY (2014) Contrasts between the phylogeographic patterns of chloroplast and nuclear DNA highlight a role for pollen-mediated gene flow in preventing population divergence in an East Asian temperate tree. Molecular Phylogenetics and Evolution, 81, 37-48.

Bao WY, Zhang Y, Lin PC, Nan P, Huang YY, Jin HF, Zhong Y (2016) Study on the pedigree geography of plant ginseng in Qinghai-Tibet Plateau. Biotechnology Bulletin, 32(12), 96-102. (in Chinese with English abstract) [鲍武印, 张阳, 林鹏程, 南蓬, 黄艳燕, 靳浩飞, 钟扬 (2016) 青藏高原 植物手参的谱系地理学研究. 生物技术通报, 32(12), 96-102.]

Barber JC, Ghebretinsae A, Graham SA (2010) An expanded phylogeny of Cuphea (Lythraceae) and a North American monophyly. Plant Systematics and Evolution, 289, 35-44.

Barnard-Kubow KB, McCoy MA, Galloway LF (2017) Biparental chloroplast inheritance leads to rescue from cytonuclear 
incompatibility. New Phytologist, 213, 1466-1476.

Barton NH, Gale KS (1993) Genetic analysis of hybrid zones. In: Hybrid Zones and the Evolutionary Process (ed. Harrison RG). Oxford University Press, New York.

Barton NH, Slatkin M (1986) A quasi-equilibrium theory of the distribution of rare alleles in a subdivided population. Heredity, 56, 409-415.

Beheregaray LB (2008) Twenty years of phylogeography: The state of the field and the challenges for the Southern Hemisphere. Molecular Ecology, 17, 3754-3774.

Bock DG, Andrew RL, Rieseberg LH (2014) On the adaptive value of cytoplasmic genomes in plants. Molecular Ecology, 23, 4899-4911.

Brauchler C, Meimberg H, Abele T, Heubl G (2005) Polyphyly of the genus Micromeria (Lamiaceae): Evidence from cpDNA sequence data. Taxon, 54, 639-650.

Brown JKM, Maan ME, Cummings ME, Summers K (2010) Evidence for selection on coloration in a Panamanian poison frog: A coalescent-based approach. Journal of Biogeography, 37, 891-901.

Byrne M, Hankinson M (2012) Testing the variability of chloroplast sequences for plant phylogeography. Australian Journal of Botany, 60, 569-574.

Charlesworth B, Morgan MT, Charlesworth D (1993) The effect of deleterious mutations on neutral molecular variation. Genetics, 134, 1289-1303.

CBOL Plant Working Group (2009) A DNA barcode for land plants. Proceedings of the National Academy of Sciences, USA, 106, 12794-12797.

Chmielewski M, Meyza K, Chybicki IJ, Dzialuk A, Litkowiec M, Burczyk J (2015) Chloroplast microsatellites as a tool for phylogeographic studies: The case of white oaks in Poland. iForest-Biogeosciences \& Forestry, 8, 765-771.

Corriveau JL, Coleman AW (1988) Rapid screening methods to detect potential biparental inheritance of plastid DNA and results for over 200 angiosperm species. American Journal of Botany, 75, 1443-1458.

Costa RJ, Wilkinson-Herbots H (2017) Inference of gene flow in the process of speciation: An efficient maximum-likelihood method for isolation-with-initial-migration model. Genetics, 205, 1597-1618.

Coyne JA, Orr HA (2004) Speciation. Sinauer Associates, Inc, Sunderland, MA.

Cutter AD (2013) Integrating phylogenetics, phylogeography and population genetics through genomes and evolutionary theory. Molecular Phylogenetics and Evolution, 69, 11721185.

Degnan JH, Rosenberg NA (2006) Discordance of species trees with their most likely gene trees. PLoS Genetics, 2, e68.

Egan AN, Vatanparast M, Cagle W (2016) Parsing polyphyletic Pueraria: Delimiting distinct evolutionary lineages through phylogeny. Molecular Phylogenetics and Evolution, 104, 44-59.
Ekhvaia J, Simeone MC, Silakadze N, Abdaladze O (2018) Morphological diversity and phylogeography of the Georgian durmast oak (Q. petraea subsp. iberica) and related Caucasian oak species in Geogria (South Caucasus). Tree Genetics \& Genomics, 14, 17.

Flood PJ, Heerwaarden JV, Becker F, Snoo CBD, Harbinson J, Aarts MGM (2016) Whole-genome hitchhiking on an organelle mutation. Current Biology, 26, 1306-1311.

Freeland JR, Kirk H, Petersen SD (2011) Molecular Ecology. Wiley-Blackwell, West Sussex, UK.

Funk DJ, Omland KE (2003) Species-level paraphyly and polyphyly: Frequency, cause, and consequences, with insights from animal mitochondrial DNA. Annual Review of Ecology and Systematics, 34, 397-423.

Garrick RC, Bonatelli IA, Hyseni C, Morales A, Pelletier TA, Perez MF, Rice E, Satler JD, Symula RE, Thomé MT, Carstens BC (2015) The evolution of phylogeographic data sets. Molecular Ecology, 24, 1164-1171.

Gavrilets S (2004) Fitness Landscapes and the Origin of Species. Princeton University Press, Princeton.

Ge XJ, Hung KH, Ko YZ, Hsu TW, Gong X, Chiang TY, ChiangYC (2015) Genetic divergence and biogeographical patterns in Amentotaxus argotaenia species complex. Plant Molecular Biology Reporter, 33, 264-280.

Gengji ZM, Li Y, Jia LK, Xia MZ, Gao QB (2018) Study on the geography of $T$. chinensis. Acta Botanica Boreali-Occidentalia Sinica, 38, 370-380. (in Chinese with English abstract) [更吉卓玛, 李彦, 贾留坤, 夏铭泽, 高庆波 (2018) 唐古特虎耳草谱系地理学研究. 西北植物学报, 38, 370-380.]

Gernandt DS, Lopez GG, Garcia SO, Liston A (2005) Phylogeny and classification of Pinus. Taxon, 54, 29-42.

Guo W, Ng WL, Wu H, Li W, Zhang L, Qiao S, Yang X, Shi X, Huang Y (2018) Chloroplast phylogeography of a widely distributed mangrove species, Excoecaria agallocha, in the Indo-West Pacific region. Hydrobiologia, 807, 333-347.

Han BC, Wei L, Yang XY, Liang XH, Wulanbateer, Shi SD (2017) Genetic diversity and lineage geographical structure of endangered plants. Inner Mongolia Forestry Science and Technology, 43(2), 16-19. (in Chinese with English abstract) [韩宝翠, 魏䂞, 杨新英, 梁晓慧, 乌兰巴特尔, 史树德 (2017) 濒危植物半日花的遗传多样性和谱系地 理结构研究. 内蒙古林业科技, 43(2), 16-19.]

Han XT, Fang MF, Li ZH, Yang J, Feng L, Zhao GF (2014) Geographical study of the distant pedigree based on the variation of the trnL intron sequence of chloroplast DNA. Chinese Traditional and Herbal Drugs, 62, 3311-3316. (in Chinese with English abstract) [韩雪婷, 房敏峰, 李忠虎, 杨佳, 冯力, 赵桂仿 (2014) 基于叶绿体DNA trnL内含子 序列变异的远志谱系地理学研究. 中草药, 62, 3311-3316.]

Hey J, Nielsen R (2007) Integration within the Felsenstein equation for improved Markov chain Monte Carlo methods 
in population genetics. Proceedings of the National Academy of Sciences, USA, 104, 2785-2790.

Hickerson MJ, Carstens BC, Cavenderbares J, Crandall KA, Graham CH, Johson JB, Rissler L, Victoriano PF, Yoder AD (2010) Phylogeography's past, present, and future: 10 years after Avise 2000. Molecular Phylogenetics and Evolution, 54, 291-301.

Hu XS (2000) A preliminary approach to the theory of geographical gene genealogy for plant genomes with three different modes of inheritance and its application. Acta Genetica Sinica, 27, 440-448.

Hu XS (2002) A review on understanding the genetic structure of population. Scientia Silvae Sinicae, 38(2), 119-128. (in Chinese with English abstract) [胡新生 (2002) 群体遗传 结构的理解. 林业科学, 38(2),119-128.]

Hu XS (2005) Tension versus ecological zones in a two-locus system. Theoretical Population Biology, 68, 119-131.

Hu XS (2008) Barriers to the spread of neutral alleles in the cytonuclear system. Evolution, 62, 2260-2278.

Hu XS (2011) Mating system and the critical migration rate for swamping selection. Genetics Research, 93, 233-254.

Hu XS (2015) Mating system as a barrier to gene flow. Evolution, 69, 1158-1177.

Hu XS, Filatov D (2016) Large-X effect in plants: Increased species divergence and reduced gene flow on Silene X-chromosome. Molecular Ecology, 25, 2609-2619.

Hu XS, He FL (2005) Background selection and population differentiation. Journal of Theoretical Biology, 235, 207-219.

$\mathrm{Hu}$ XS, Li BL (2002) Seed and pollen flow and cline discordance among genes with different modes of inheritance. Heredity, 88, 212-217.

Hu XS, Yeh FC, Hu Y, Deng LT, Ennos RA, Chen XY (2017) High mutation rates explain low population genetic divergence at copy-number-variable loci in Homo sapiens. Scientific Reports, 7, 43178.

Huang CY, Ayliffe MA, Timmis, Jeremy N (2003) Direct measurement of the transfer rate of chloroplast DNA into the nucleus. Nature, 422, 72-76.

Huang J, Yang X, Zhang C, Yin X, Liu S, Li X (2015) Development of chloroplast microsatellite markers and analysis of chloroplast diversity in Chinese jujube (Ziziphus jujuba Mill.) and wild jujube (Ziziphus acidojujuba Mill.). PLoS ONE, 10, e0134519.

Hudson RR, Coyne JA (2002) Mathematical consequences of the genealogical species concept. Evolution, 56, 1557-1565.

Hudson RR, Slatkin M, Maddison WP (1992) Estimation of levels of gene flow from DNA sequence data. Genetics, 132, 583-589.

Hung KH, Schaal BA, Hsu TW, Chiang YC, Peng CI, Chiang TY (2009) Phylogenetic relationships of diploid and polyploid species in Ludwigia sect. Isnardia (Onagraceae) based on chloroplast and nuclear DNAs. Taxon, 58, 1216-1225.

Huttunen S, Ignatov MS (2010) Evolution and taxonomy of aquatic species in the genus Rhynchostegium (Brachytheciaceae, Bryophyta). Taxon, 59, 791-808.

Ikeda H, Setoguchi H (2009) The homogenous genetic structure and inferred unique history of range shifts during the Pleistocene climatic oscillations of Arcterica nana (Maxim.) Makino (Ericaceae). Journal of Plant Research, 122, 141-151.

Ikeda H, Setoguchi H (2013) A multilocus sequencing approach reveals the cryptic phylogeographical history of Phyllodoce nipponica Makino (Ericaceae). Biological Journal of the Linnean Society, 110, 214-226.

Johnson LA, Chan LM, Weese TL, Busby LD, McMurry S (2008) Nuclear and cpDNA sequences combined provide strong inference of higher phylogenetic relationships in the phlox family (Polemoniaceae). Molecular Phylogenetics and Evolution, 48, 997-1012.

Kim ST, Donoghue MJ (2008) Molecular phylogeny of Persicaria (Persicarieae, Polygonaceae). Systematic Botany, 33, 77-86.

Kormutak A, Galgoci M, Sukenikova D, Bolecek P, Libantova J, Gomory D (2018) Maternal inheritance of chloroplast DNA in Pinus mugo Turra: A case study of Pinus mugo $\times$ Pinus sylvestris. Plant Systematics and Evolution, 304, 71-76.

Lavin M, Doyle JJ, Palmer JD (1990) Evolutionary significance of the loss of the chloroplast-DNA inverted repeat in the Leguminosae subfamily Papilionoideae. Evolution, 44, 390-402.

Levin RA, Wagner WL, Hoch PC, Nepokroeff MM, Pires JC, Zimmer EA, Sytsma KJ (2003) Family-level relationships of Onagraceae based on chloroplast $r b c \mathrm{~L}$ and $n d h \mathrm{~F}$ data. American Journal of Botany, 90, 107-115.

Lexer C, Mangili S, Bossolini E, Forest F, Stolting KN, Pearman PB, Zimmermann NE, Salamin N (2013) Next generation' biogeography: Towards understanding the drivers of species diversification and persistence. Journal of Biogeography, 40, 1013-1022.

Li ZH, Liu ZL, Wang ML, Qian ZQ, Zhao P, Zhu J, Yang YX, Yan XH, Li YJ, Zhao GF (2014) Review of speciation formation in the presence of gene flow: Evolution of reproductive isolation mechanism. Biodiversity Science, 22, 88-96. (in Chinese with English abstract) [李忠虎, 刘占林, 王玛丽, 钱增强, 赵鹏, 祝娟, 杨一欣, 阎晓吴, 李银军, 赵桂仿 (2014) 基因流存在条件下的物种形成研究述评: 生殖隔离机制进化. 生物多样性, 22, 88-96.]

Liu YF, Huang HW (2009) Advances in research on gene flow dynamics and adaptive evolution of plant populations. Chinese Bulletin of Botany, 44, 351-362. (in Chinese with English abstract) [刘义飞, 黄宏文 (2009) 植物居群的基 因流动态及其相关适应进化的研究进展. 植物学报, 44, 351-362.]

Lu BR, Xia H, Yang X, Jin X, Liu P, Wang W (2009) The significance of hybridization-introgression evolution theory in transgenic escape and its environmental risk assessment 
and research. Biodiversity Science, 17, 362-377. (in Chinese with English abstract) [卢宝荣, 夏辉, 杨箫, 金金金, 刘苹, 汪魏 (2009) 杂交-渐渗进化理论在转基因逃逸及 其环境风险评价和研究中的意义. 生物多样性, 17, 362-377.]

Martin W, Rujan T, Richly E, Hansen A, Cornelsen S, Lins T, Leister D, Stoebe B, Hasegawa M, Penny D (2002) Evolutionary analysis of Arabidopsis, cyanobacterial, and chloroplast genomes reveals plastid phylogeny and thousands of cyanobacterial genes in the nucleus. Proceedings of the National Academy of Sciences, USA, 99, 12246-12251.

Matos JA, Schaal BA (2010) Chloroplast evolution in the Pinus montezumae complex: A coalescent approach to hybridization. Evolution, 54, 1218-1233.

Meirmans PG, Godbout J, Lamothe M, Thompson SL, Isabel N (2017) History rather than hybridization determines population structure and adaptation in Populus balsamifera. Journal of Evolutionary Biology, 30, 2044-2058.

Meng LH, Yang HL, Wu GL, Wang YJ (2008) Study on the pedigree geography of Hippophae rhamnoides L. based on chloroplast DNA trnL-F sequence. Journal of Systematics and Evolution, 46, 32-40. (in Chinese with English abstract) [孟丽华, 杨慧玲, 吴桂丽, 王玉金 (2008) 基于叶绿体 DNA trnL-F序列研究肋果沙棘的谱系地理学. 植物分类 学报, 46, 32-40.]

Muir G, Filatov D (2007) A selective sweep in the chloroplast DNA of dioecious Silene (section Elisanthe). Genetics, 177, 1239-1247.

Nosil P (2012) Ecological Speciation. Oxford University Press, Oxford.

Nie ZL, Wen J, Sun H, Bartholomew B (2005) Monophyly of Kelloggia torrey ex Benth. (Rubiaceae) and evolution of its intercontinental disjunction between Western North America and Eastern Asia. American Journal of Botany, 92, 642-652.

Palmer JD (1985) Comparative organization of chloroplast genomes. Annual Review of Genetics, 19, 325-354.

Palumbi SR, Cipriano F, Hare MP (2001) Predicting nuclear gene coalescence from mitochondrial data: The three-times rule. Evolution, 55, 859-868.

Perry AS, Wolfe KH (2002) Nucleotide substitution rates in legume chloroplast DNA depend on the presence of the inverted repeat. Journal of Molecular Evolution, 55, 501-508.

Porter JM, Johnson LA, Wilke D (2010) Phylogenetic systematics of Ipomopsis (Polemoniaceae): Relationships and divergence times estimated from chloroplast and nuclear DNA sequences. Systematic Botany, 35, 181-200.

Provan J, Powell W, Hollingsworth PM (2001) Chloroplast microsatellites: New tools for studies in plant ecology and evolution. Trends in Ecology and Evolution, 16, 142-147.

Qiu YX, Fu CX, Comes HP (2011) Plant molecular phylogeography in China and adjacent regions: Tracing the genetic imprints of Quaternary climate and environmental change in the world's most diverse temperate flora. Molecular Phylogenetics and Evolution, 59, 225-244.

Ramdhani S, Barker NP, Baijnath H (2009) Rampant non-monophyly of species in Kniphofia Moench (Asphodelaceae) suggests a recent Afromontane radiation. Taxon, 58, 11411152.

Ramdhani S, Barker NP, Cowling RM (2011) Revisiting monophyly in Haworthia duval (Asphodelaceae): Incongruence, hybridization and contemporary. Taxon, 60, 1001-1014.

Ramos-Ortiz S, Oyama K, Rodrigue-Correa H, Gonzalez-Rodriguez A (2016) Geographic structure of genetic and phenotypic variation in the hybrid zone between Quercus affinis and Q. laurina in Mexico. Plant Species Biology, 31, 219-232.

Renner SS (2016) Available data point to a 4-km-high Tibetan Plateau by 40 Ma but 100 molecular-clock papers have linked supposed recent uplift to young node ages. Journal of Biogeography, 43, 1479-1487.

Renoult JP, Kjellberg F, Grout C, Santoni S, Khadari B (2009) Cyto-nuclear discordance in the phylogeny of Ficus section Galoglychia and host shifts in plant-pollinator associations. BMC Evolutionary Biology, 9, 248.

Rosenberg NA (2003) The shapes of neutral gene genealogies in two species: Probabilities of monophyly, paraphyly, and polyphyly in a coalescent model. Evolution, 57, 1465-1477.

Schaal BA, Hayworth DA, Olsen KM, Rauscher JT, Smith WA (2010) Phylogeographic studies in plants: Problems and prospects. Molecular Ecology, 7, 465-474.

Schonswetter P, Suda J, Popp M, Weiss-Schneeweiss H, Brochmann C (2007) Circumpolar phylogeography of Juncus biglumis (Juncaceae) inferred from AFLP fingerprints, cpDNA sequences nuclear DNA content and chromosome numbers. Molecular Phylogenetics and Evolution, 42, 92-103.

Slatkin M, Barton NH (1989) A comparison of three indirect methods for estimating average levels of gene flow. Evolution, 43, 1349-1368.

Smith JF, Ooi MTY, Clark JL (2018) Incipient speciation in a neotropical Gesneriaceae: Columnea kucyniakii is nested within C. strigose. Plant Systematics and Evolution, 304, 511-519.

Song MS, Yue JP, Sun H, Li ZM (2011) Phylogeographical study on Primula poissonii (Primulaceae) from Hengduan Mountains. Plant Diversity and Resources, 33, 91-100. (in Chinese with English abstract) [宋敏舒, 乐雯培, 孙航, 李 志敏 (2011) 横断山地区海仙报春的谱系地理学研究.植 物分类与资源学报, 33, 91-100.]

Stegemann S, Hartmann S, Ruf S, Bock R (2003) High-frequency gene transfer from the chloroplast genome to the nucleus. Proceedings of the National Academy of Sciences, USA, 100, 8828-8833.

Strauss SH, Palmer JD, Howe GT, Doerksen AH (1988) 
Chloroplast genomes of two conifers lack a large inverted repeat and are extensively rearranged. Proceedings of the National Academy of Sciences, USA, 85, 3898-3902.

Sun YS, Abbott RJ, Li LL, Li L, Zou JB, Liu JQ (2014) Evolutionary history of purple cone spruce (Picea purpurea) in the Qinghai-Tibet Plateau: Homoploid hybrid origin and pleistocene expansion. Molecular Ecology, 23, 343-359.

Syring J, Farrell K, Businsky R, Cronn R, Liston A (2007) Widespread genealogical nonmonophyly in species Pinus subgenus Strobus. Systematic Botany, 56, 163-181.

Tajima F (1983) Evolutionary relationships of DNA sequences in finite populations. Genetics, 105, 437-460.

Templeton AR (1998) Nested clade analysis of phylogeographic data: Testing hypotheses about gene flow and population history. Molecular Ecology, 7, 381-397.

Vachon N, Freeland JR (2011) Phylogeographic inferences from chloroplast DNA: Quantifying the effects of mutations in repetitive and non-repetitive sequences. Molecular Ecology Resources, 11, 279-285.

Valcarcel V, Fiz O, Vargas P (2003) Chloroplast and nuclear evidence for multiple origins of polyploids and diploids of Hedera (Araliaceae) in the Mediterranean basin. Molecular Phylogenetics and Evolution, 27, 1-20.

Wang JL, Gao QB, Fu PC, Gulzar K, Chen SL, Zhang FQ (2014) Phylogeography of Spiraea mongolica (Rosaceae) on the Qinghai-Tibetan Plateau and adjacent highlands. Acta Botanica Boreali-Occidentalia Sinica, 34, 1981-1991. (in Chinese with English abstract) [王久利, 高庆波, 付鹏程, Khan Gulzar, 陈世龙, 张发起 (2014) 青藏高原及其毗邻 山区蒙古绣线菊谱系地理学研究. 西北植物学报, 34, 1981-1991.]

Wang M, Zhao HX, Wang L, Wang T, Yang RW, Wang XL, Zhou YH, Ding CB, Zhang L (2013) Potential use of DNA barcoding for the identification of Salvia based on cpDNA and nrDNA sequences. Genetics, 528, 206-215.

Wang MN, Qiao Q, Zhang RJ, Hu PW, Yang G, Chen HF (2011) Studies on the community feature comparison and phylogeography of relic plant Bretschneidera sinensis in Nankun and Daling Mountains, Guangdong Province. Guihaia, 31, 789-794. (in Chinese with English abstract) [王美 娜, 乔琦, 张荣京, 胡普炜, 杨国, 陈红锋 (2011) 广东 南昆山与大岭山子遗植物伯乐树群落特征比较与谱系地 理学研究. 广西植物, 31, 789-794.]

Wang RJ, Cheng CL, Su TM, Chang CC, Wu CL, Chaw SM (2008) Dynamics and evolution of the inverted repeat/large single copy junctions in the chloroplast genomes of monocots. BMC Evolutionary Biology, 8, 36.

Wang XX, Yue JP, Sun H, Li ZM (2011) Phylogeographical study on Eriophyton wallichii (Labiatae) from alpine scree of Qinghai-Tibetan Plateau. Plant Diversity and Resources, 33, 605-614. (in Chinese with English abstract) [王晓雄, 乐雯培, 孙航, 李志敏 (2011) 青藏高原高山流石滩特有 植物绵参的谱系地理学研究. 植物分类与资源学报, 33,
605-614.]

Wang Y, Hey J (2010) Estimating divergence parameters with small samples from a large number of loci. Genetics, 184, 363-379.

Wang Y, Shang H, Gu YF, Wei HJ, Zhao GH, Dai XL, Yan YH (2015) A new cryptic hybrid species of Adiantum L. (Pteridaceae) identified by nuclear and chloroplast DNA sequences. Chinese Science Bulletin, 60, 922-932. (in Chinese with English abstract) [王芗, 商辉, 顾钰峰, 韦宏金, 赵国 华, 戴锡玲, 严岳鸿 (2015) 用核DNA和叶绿体DNA序

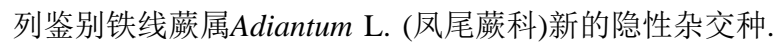
科学通报, 60, 922-932.].

Wang YZ, Mao RB, Liu Y, Li JM, Dong Y, Li ZY, Smith JF (2011) Phylogenetic reconstruction of Chirita and allies (Gesneriaceae) with taxonomic treatments. Journal of Systematics and Evolution, 49, 50-64.

Watano Y, Kanai A, Tani N (2004) Genetic structure of hybrid zones between Pinus pumila and P. parviflora var. pentaphylla (Pinaceae) revealed by molecular hybrid index analysis. American Journal of Botany, 9, 65-72.

Wellborn GA, Langerhans RB (2015) Ecological opportunity and the adaptive diversification of lineages. Ecology and Evolution 5, 176-195.

Wen J, Zhang JQ, Nie ZL, Zhong Y, Sun H (2014) Evolutionary diversifications of plants on the Qinghai-Tibetan Plateau. Frontiers in Genetics, 5, 4.

Wolf JB (2009) Cytonuclear interactions can favor the evolution of genomic imprinting. Evolution, 63, 1364-1371.

Wolfe KH, Li WH, Sharp PM (1987) Rates of nucleotide substitution vary greatly among plant mitochondrial, chloroplast, and nuclear DNAs. Proceedings of the National Academy of Sciences, USA, 84, 9054-9058.

Wright S (1969) Evolution and the Genetics of Populations. Vol. 2. The Theory of Gene Frequencies. University Chicago Press, Chicago.

Wright S (1977) Evolution and the Genetics of Populations. Vol. 3. Experimental Results and Evolutionary Deductions. University Chicago Press, Chicago.

Wu ZY, Wu SG (1996) A proposal for a new floristic kingdom (realm) - the E. Asiatic kingdom, its delimitation and characteristics. In: Proceedings of the First International Symposium on Floristic Characteristics and Diversity of East Asian Plants (eds Zhang AL, Wu SG), pp. 3-42. Higher Education Press, Beijing \& Springer-Verlag, Berlin.

Xing SC, Liu CJ (2008) Progress in chloroplast genome analysis. Progress in Biochemistry and Biophysics, 35(1), 1-8. (in Chinese with English abstract) [邢少辰, Liu CJ (2008) 叶绿体基因组研究进展. 生物化学与生物物理进 展, 35(1), 1-8.]

Yang YC, Kung TL, Hu CY, Lin SF (2015) Development of primer pairs from diverse chloroplast genomes for use in plant phylogenetic research. Genetics and Molecular Research, 14, 14857-14870. 
Young ND (1996) Concordance and discordance: A tale of two hybrid zones in the Pacific Coast irises (Iridaceae). American Journal of Botany, 83, 1623-1629.

Yu HB, Zhang YL (2013) Advances in phylogeography of alpine plants in the Tibetan Plateau and adjacent regions. Acta Botanica Boreali-Occidentalia Sinica, 33, 1268-1278. (in Chinese with English abstract) [于海涁, 张镱锂 (2013) 青 藏高原及其周边地区高山植物谱系地理学研究进展. 西 北植物学报, 33, 1268-1278.]

Zeng YF, Zhang JG, Duan AG, Abuduhamiti B (2012) Genetic structure of Populus hybrid zone along the Irtysh River provides insight into plastid-nuclear incompatibility. Scientific Reports, 6, 28043.

Zhang FQ, Gao QB, Duan YZ, Zhang DJ, Chen SL (2012) Phylogeography of Spiraea alpine (Rosaceae) in Hengduan Mountain. Guihaia, 32, 617-623. (in Chinese with English abstract) [张发起, 高庆波, 段义忠, 张得钧, 陈世龙 (2012) 横断山区高山绣线菊的谱系地理学研究. 广西植 物, 32, 617-623.]

Zhang T, Li ZZ, Liu YL, Jiang ZW, Huang HW (2007) Genetic diversity, gene introgression and homoplasy in sympatric populations of the genus Actinidia as revealed by chloroplast microsatellite markers. Biodiversity Science, 15, 1-22. (in Chinese with English abstract) [张田, 李作洲, 刘亚令, 姜
正旺, 黄宏文 (2007) 猕猴桃属植物的cpSSR遗传多样性 及其同域分布物种的杂交渐渗与同塑. 生物多样性, 15 , 1-22.]

Zhang Q, Yang R, Wang Q, Liu JQ (2005) Phylogeography of Juniperus przewalskii (Cupressaceae) inferred from the chloroplast DNA trnT-trnF sequence variation. Acta Phytotaxonomica Sinica, 43, 503-512. (in Chinese with English abstract) [张茜, 杨瑞, 王钦, 刘建全 (2005) 基于 叶绿体DNA trnT-trnF序列研究祁连圆柏的谱系地理学. 植物分类学报, 43, 503-512.]

Zhang X, Shen S, Wu F, Wang Y (2017) Inferring genetic variation and demographic history of Michelia yunnanensis Franch. (Magnoliaceae) from chloroplast DNA sequences and microsatellite markers. Frontiers in Plant Sciences, 8, 583.

Zhang XM, Li DZ, Gao LM (2012) Phylogeographical study on Taxus wallichiana var. mairei (Lemee \& Leveille) L.K.Fu \& Nan Li. Acta Botanica Boreali-Occidentalia Sinica, 32, 1983-1989. (in Chinese with English abstract) [张雪梅, 李德铢, 高连明 (2012) 南方红豆杉谱系地理 学研究. 西北植物学报, 32, 1983-1989.]

(责任编委：王艇 责任编辑: 黄祥忠) 